\title{
MOLECULAR MECHANISMS OF ANTINEOPLASTIC ACTION OF AN ANTICANCER DRUG ELLIPTICINE
}

\author{
Marie Stiborova $^{\mathrm{a}}$, Martina Rupertova ${ }^{\mathrm{a}}$, Heinz H. Schmeiser ${ }^{\mathrm{b}}$, Eva Frei ${ }^{\mathrm{b}}$ \\ a Department of Biochemistry, Faculty of Science, Charles University, Albertov 2030, 12840 Prague 2, Czech Republic \\ ${ }^{b}$ Division of Molecular Toxicology, German Cancer Research Center, Im Neuenheimer Feld 280, 69120 Heidelberg, \\ Germany \\ e-mail: stiborov@natur.cuni.cz
}

Received: April 4, 2006; Accepted: May 16, 2006

Key words: Ellipticine/Anticancer drug/Cytochrome P450/Peroxidase/Mechanism of action/DNA adducts

\begin{abstract}
Ellipticine is a potent antineoplastic agent exhibiting the multimodal mechanism of its action. This article reviews the mechanisms of predominant pharmacological and cytotoxic effects of ellipticine and shows the results of our laboratories indicating a novel mechanism of its action. The prevalent mechanisms of ellipticine antitumor, mutagenic and cytotoxic activities were suggested to be intercalation into DNA and inhibition of DNA topoisomerase II activity. We demonstrated a new mode of ellipticine action, formation of covalent DNA adducts mediated by its oxidation with cytochromes P450 (CYP) and peroxidases. The article reports the molecular mechanism of ellipticine oxidation by CYPs and identifies human and rat CYPs responsible for ellipticine metabolic activation and detoxication. It also presents a role of peroxidases (i.e. myeloperoxidase, cyclooxygenases, lactoperoxidase) in ellipticine oxidation leading to ellipticine-DNA adducts. The 9-hydroxy- and 7-hydroxyellipticine metabolites formed by CYPs and the major product of ellipticine oxidation by peroxidases, the dimer, in which the two ellipticine skeletons are connected via $\mathrm{N}^{6}$ of the pyrrole ring of one ellipticine molecule and C9 in the second one, are the detoxication metabolites. On the contrary, 13-hydroxy- and 12-hydroxyellipticine, produced by ellipticine oxidation with CYPs, the latter one formed also spontaneously from another CYP- and peroxidase-mediated metabolite, ellipticine $N^{2}$-oxide, are metabolites responsible for formation of two ellipticine-derived deoxyguanosine adducts in DNA. The results reviewed here allow us to propose species, two carbenium ions, ellipticine-13-ylium and ellipticine-12-ylium, as reactive species generating two major DNA adducts seen in vivo in rats treated with ellipticine. The study forms the basis to further predict the susceptibility of human cancers to ellipticine.
\end{abstract}

\section{INTRODUCTION}

Ellipticine (5,11-dimethyl-6H-pyrido[4,3-b]carbazole), an alkaloid isolated from Apocyanaceae plants (i.e. Ochrosia borbonica, Excavatia coccinea), and several its derivatives exhibit significant antitumor and anti-HIV activities ${ }^{1-3}$. This compound is one of the simplest naturally occurring alkaloids, having a planar structure ${ }^{4}$. It was first isolated in 1959 from the leaves of the evergreen tree Ochrosia elliptica, which grows wild in Oceania ${ }^{4}$. Ellipticine and its more soluble derivatives (9-hydroxyellipticine, 9hydroxy- $N^{2}$-methylellipticinium, 9-chloro- $N^{2}$-methylellipticinium and 9-methoxy- $N^{2}$-methylellipticinium) exhibit promising results for the treatment of osteolytic breast cancer metastases, kidney cancer, brain tumors and acute myeloblastic leukemia ${ }^{5-9}$. The main reason for the interest in ellipticine and its derivatives for clinical purposes is their high efficiencies against several types of cancer, their rather limited toxic side effects and their complete lack of hematological toxicity ${ }^{5}$. Nevertheless, mutagenicity of ellipticines should be evaluated as a potential risk factor for these anticancer agents. Most ellipticines are mutagenic to Salmonella typhimurium Ames tester strains, bacteri- ophage T4, Neurospora crassa, and mammalian cells and induce prophage lambda in Escherichia coli ${ }^{10}$.

\section{MECHANISMS OF THE CYTOTOXICITY AND ANTICANCER ACTIVITY OF ELLIPTICINES}

Ellipticines are cytostatics, whose precise mechanisms of action have not yet been explained. The multimodal mechanism of their action was demonstrated ${ }^{5}$. Therefore, ellipticine antineoplastic activity may result from alternative cytotoxic events. It was suggested that the prevalent mechanisms of ellipticine antitumor, mutagenic and cytotoxic activities are (i) intercalation into DNA and (ii) inhibition of DNA topoisomerase II activity ${ }^{5}$.

The size and shape of the ellipticine chromophore closely resemble those of a purine-pyrimidine complementary base pair, providing favorable conditions for its intercalation in double-stranded DNA. Furthermore, the polycyclic aromatic character of the molecule may, moreover, result in tight interactions with appropriately conformed hydrophobic regions in DNA. Interactions between the methyl groups of the drug and the thymine 

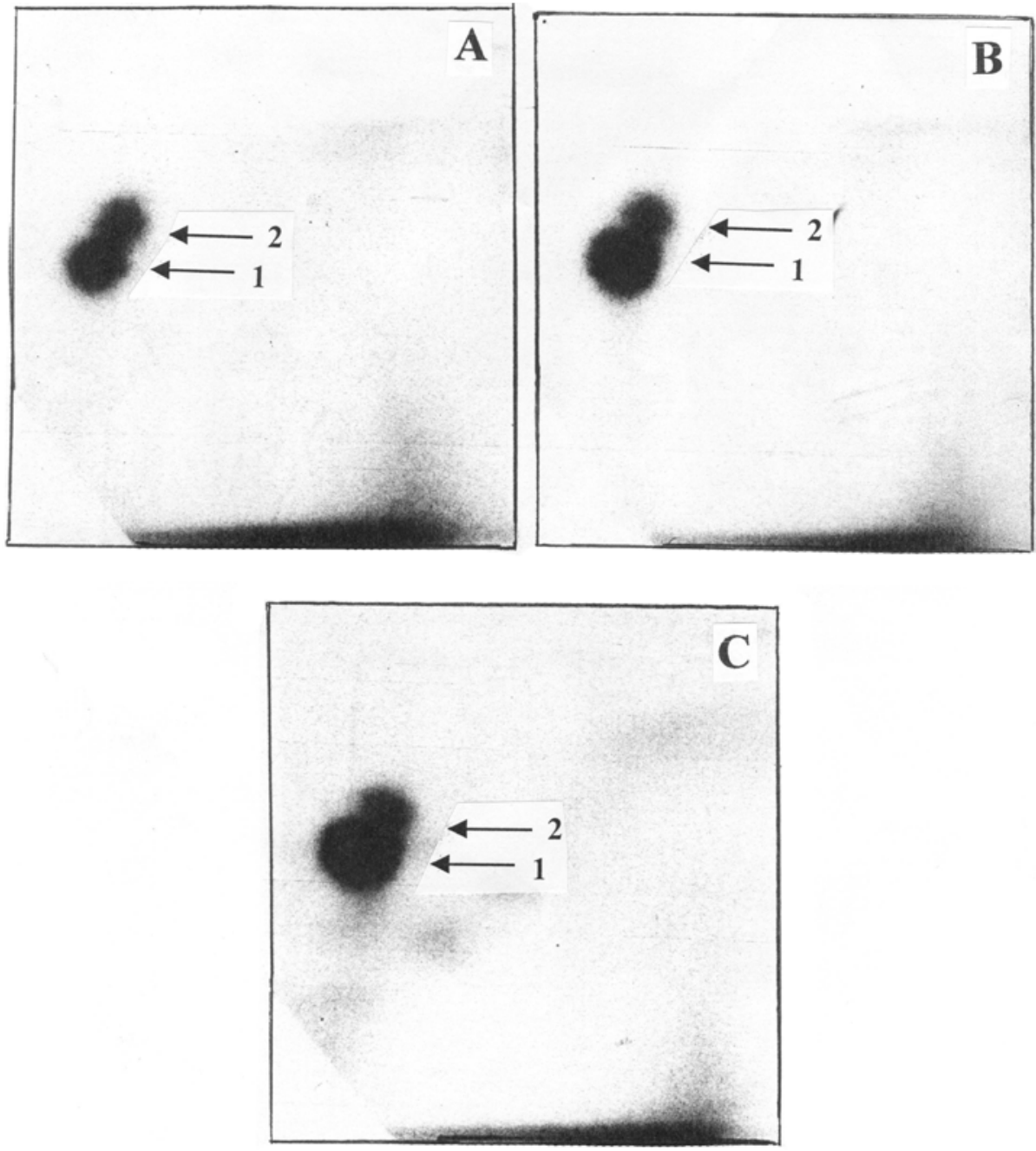

Fig. 1. Autoradiographic profiles of ellipticine-derived DNA adducts generated by human CYP3A4 [25 pmol (A), 50 pmol (B) and 100 pmol (C)] analyzed with the ${ }^{32} \mathrm{P}$-postlabeling assay [adapted from reference ${ }^{24}$ ].

bases at the intercalation site appear important in determining the orientational preferences of the drug ${ }^{11-12}$.

The mechanism of ellipticine action as the inhibitor of topoisomerase II has also been extensively studied ${ }^{13-15}$. Ellipticine acts by stimulating topoisomerase II-mediated DNA breakage. It is likely that formation of a ternary complex between topoisomerase II, DNA, and drug is critical for nucleic acid breakage and subsequent cell death. Topoisomerase II was identified as the primary cellular target of the drug. Furthermore, ellipticine did not inhibit enzyme-mediated DNA religation, suggesting that it stimulates DNA breakage by enhancing the forward rate of cleavage. Froelich-Ammon and coworkers ${ }^{15}$ postulated that ellipticine enters the ternary complex through its prior association with either DNA or the enzyme and does not require the presence of a preformed topoisomerase II-DNA complex.

Numerous studies have reported the involvement of p53 tumor suppressor protein in ellipticine cytotoxic effect $^{16-19}$. 9-Hydroxyellipticine treatment caused induction of apoptosis in the $\mathrm{G} 1$ phase of the cell cycle in mutant p53 transfected Saos-2 cells, but not in p53-deficient parental Saos-2 cells ${ }^{17}$. Ellipticine and 9-hydroxyellipticine cause selective inhibition of $\mathrm{p} 53$ protein phosphorylation via kinase inhibition in several human cancer cell lines such as Lewis lung carcinoma and human colon cancer cell line SW480 ${ }^{18}$, and this correlated with their cytotoxic activity. Moreover, accumulation of dephosphorylated mutant p53 may induce apoptosis ${ }^{18}$. Ellipticine has also been found to restore the transcription function of mutant p53, and this property may contribute to resisting tumor cell lines expression mutant ${ }^{16}$. Ellipticine causes an increase in the protein expression of $\mathrm{p} 53$ and, $\mathrm{p} 21 / \mathrm{WAF} 1$ and $\mathrm{KIP} 1 / \mathrm{p} 27$, but not of WAF1/p21 in human breast adenocarcinoma MCF-7 cells treated with ellipticine, and growth inhibition by this compound is also induced by mitochondrial proapoptotic pathways in these cells ${ }^{19}$. In addition, ellipticines uncouple mitochondrial oxidative phosphorylation ${ }^{20}$, and thereby disrupt the energy balance of cells.

Studies on the mechanisms of the cytotoxic and anticancer activity of ellipticine have also shown that these activities might be due to induction of endoplasmic reticulum stress ${ }^{21}$. 
Table 1. Correlation coefficients (r) between CYP-linked catalytic activities and levels of ellipticine metabolites or ellipticine-DNA adducts formed by human hepatic microsomes

\begin{tabular}{|c|c|c|c|c|c|c|c|c|}
\hline & 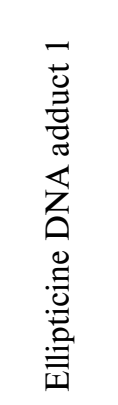 & 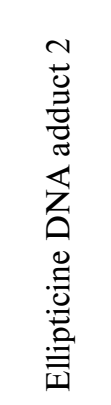 & 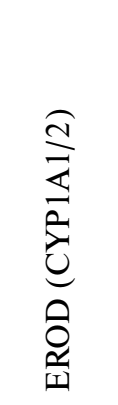 & 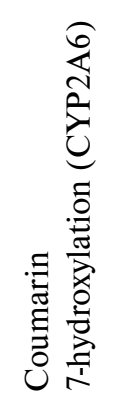 & 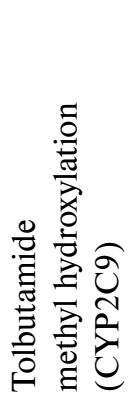 & 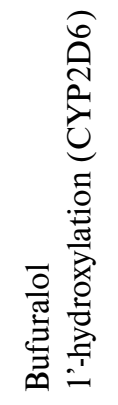 & 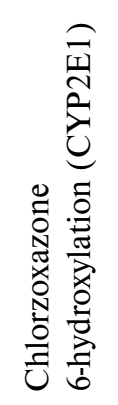 & 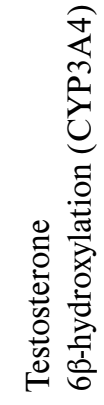 \\
\hline 9-hydroxyellipticine & -0.080 & -0.332 & $0.822^{\dagger}$ & -0.278 & -0.321 & -0.103 & 0.299 & 0.233 \\
\hline 12-hydroxyellipticine & 0.406 & 0.190 & 0.134 & -0.251 & -0.730 & -0.470 & -0.195 & 0.032 \\
\hline 13-hydroxyellipticine & $0.942^{*}$ & $0.912^{\dagger}$ & 0.042 & -0.433 & -0.228 & 0.169 & 0.237 & $0.910^{*}$ \\
\hline 7-hydroxyellipticine & 0.295 & 0.096 & 0.642 & 0.168 & 0.170 & -0.336 & 0.575 & 0.001 \\
\hline$N^{2}$-oxide of ellipticine & $0.810^{\ddagger}$ & $0.920^{*}$ & 0.346 & -0.143 & -0.143 & 0.138 & 0.024 & $0.802^{\ddagger}$ \\
\hline
\end{tabular}

${ }^{*} p<0.001 ;{ }^{\dagger} p<0.01 ;{ }^{\ddagger} p<0.05 \mathrm{n}=8$

Data used for correlation analysis are shown in our previous work ${ }^{27}$. Statistical association between CYP-linked catalytic activities in human hepatic microsomal samples and levels of individual ellipticine metabolites or of ellipticine-DNA adducts formed by the same microsomes were determined by the correlation coefficients using version 6.12 Statistical Analysis System software. Correlation coefficients were based on a sample size of 8 . All $P$ s are two-tailed and considered significant at the 0.05 level.

\subsection{Covalent binding of ellipticine to DNA as a novel mode of ellipticine action}

It is evident that the explanations of anticancer activity mentioned above are based on mechanisms of nonspecific drug actions. The transport of highly hydrophobic ellipticine molecules across cell membranes into cells (including both tumor and healthy cells) is also nonspecific. However, this sharply contrasts with specificity of antineoplastic activity of ellipticines against only several cancer diseases. The specificity of antitumor activity of ellipticines should, hence, be a consequence of other mechanisms of their action, which have not been elucidated as yet.

Recently, we confirmed this suggestion. We found a novel mode for the ellipticine action, demonstrating for the first time that ellipticine covalently binds to DNA in vitro and in vivo after being enzymatically activated ${ }^{22-31}$.

Based on data found by us ${ }^{22-31}$, ellipticine might be considered a drug, whose pharmacological efficiency and/ or genotoxic side effects are dependent on its cytochrome P450 (CYP)- and/or peroxidase-mediated activation in target tissues.

\subsubsection{Oxidation of ellipticine by cytochromes $P 450$ plays} a role both in its detoxication and in activation to species binding to DNA

We have demonstrated that CYP enzymes expressed in human and rat livers are effective in activating ellipticine leading to species forming the covalent DNA adducts in vitro (see Fig. 1 for formation of ellipticine-derived DNA adducts by different concentrations of human CYP3A4).
The structure of all ellipticine metabolites produced by CYPs was characterized, the participation of individual human and rat CYP enzymes in their formation identified and the metabolites responsible for DNA binding elucidated $^{27,31}$. HPLC was found to be suitable method for separation of individual ellipticine metabolites (Fig. 2). Four of ellipticine metabolites were identified to be C-hydroxylated derivatives of ellipticine, 7-hydroxy-, 9-hydroxy-, 12-hydroxy- and 13-hydroxyellipticine and one is the $N^{2}$ oxide of ellipticine (Figs. 2 and 3) (ref. ${ }^{27,31}$ ). Employing three experimental approaches [correlation of CYP-linked enzyme activities in human hepatic microsomes with the amounts of ellipticine metabolites generated by the same microsomes, the effect of selective CYP inhibitors, and use of heterologous baculovirus expression systems of human CYPs (Supersomes ${ }^{\mathrm{TM}}$ )] CYP enzymes responsible for the oxidation of ellipticine in human hepatic microsomes were resolved ${ }^{27,31}$.

The formation of 9-hydroxy and 7-hydroxyellipticine is attributable to the activity of CYP1A1/2 as follows from correlation tendencies of their formation with ethoxyresorufin $O$-deethylase activity, a marker for CYP 1 A $1 / 2$ (Tab. 1). Furthermore, $\alpha$-naphthophlavone and furafylline, selective CYP1A1/2 inhibitors, decreased formation of these metabolites efficiently ${ }^{27,31}$. The formation of 13-hydroxyellipticine was highly correlated with 6 6 -hydroxylation of testosterone, a marker for CYP3A4. A significant correlation was also seen between production of $N^{2}$-oxide of ellipticine and $6 \beta$-hydroxylation of testosterone ${ }^{27}$. These results indicate that 13 -hydroxyellipticine and $N^{2}$ oxide of ellipticine are mainly generated by CYP3A4 in 
human livers (Tab. 1). Indeed ketoconazole, an inhibitor of CYP3A4 inhibited generation of 13-hydroxyellipticine and ellipticine $N^{2}$-oxide significantly ${ }^{31}$.

Utilizing microsomes of Baculovirus transfected insect cells (Supersomes ${ }^{\mathrm{TM}}$ ) containing recombinantly expressed human CYPs and NADPH:CYP reductase corroborated the results obtained with human hepatic microsomes, except for very effective $N^{2}$-oxidation by CYP2D6 in this system $^{27}$ (Fig. 4). Human recombinant CYP1A1 and 1A2 were the major enzymes oxidizing ellipticine to 9-hydroxyand 7-hydroxyellipticine. Moreover, CYP1B1 and 2D6 were also efficient to catalyze these reactions, but to a lower extent. 12-Hydroxyellipticine was found to be a minor product of ellipticine oxidation by human recombinant CYP enzymes. Low levels of this metabolite are generated only in incubations containing CYP3A4 and 2C9. The major enzyme oxidizing ellipticine to 13-hydroxyellipticine is human recombinant CYP3A4, followed by CYP1A2, 2D6 and 2C9. The human recombinant CYP3A4 enzyme is also able to form the metabolite $N^{2}$-oxide of ellipticine, but human recombinant CYP2D6 is much more effective in generating this product under the conditions used (Fig. 4). Because CYP3A4 is the most abundant CYP species in human liver $(\sim 30 \%)$ (ref. $\left.{ }^{32}\right)$, oxidation of ellipticine to 13-hydroxyellipticine and $N^{2}$-oxide of ellipticine should be the major metabolic pathway of the drug in human livers. Indeed, the predominant ellipticine metabolite formed by the human hepatic microsomal samples is 13-hydroxyellipticine followed by $N^{2}$-oxide of ellipticine ${ }^{27}$. The CYP enzymes analogous to those of human livers were found to be responsible for oxidation of ellipticine in rat hepatic microsomes. 7-Hydroxy- and 9-hydroxyellipticine are generated mainly by rat CYP1A1/2, while 13-hydroxyellipticine and ellipticine $N^{2}$-oxide by CYP3A1. Similarities in pattern of ellipticine metabolites and CYP enzymes responsible for their generation in human and rat hepatic microsomal systems underline the suitability of rat species as a model to evaluate human susceptibility to ellipticine ${ }^{24,27,31}$. Therefore, rats were used as model organisms to study the fate of ellipticine in vivo ${ }^{25}$.

Using ${ }^{32} \mathrm{P}$-postlabeling method ${ }^{33}$ we found that during

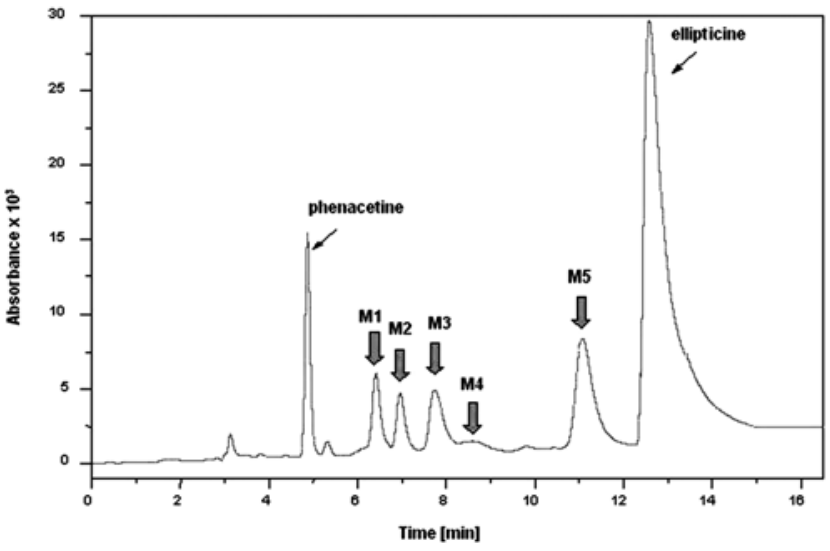

Fig. 2. HPLC chromatogram of ellipticine metabolites formed by human microsomes. M1 = 9-hydroxyellipticine, M2 = 12-hydroxyellipticine, M3 = 13-hydroxyellipticine, $\mathrm{M} 4$ = 7-hydroxyellipticine, M5 = ellipticine $N^{2}$-oxide, [adapted from reference ${ }^{31}$ ].

the ellipticine oxidation by CYPs two major and several minor adducts are generated in DNA (Fig. 1). Employing a panel of different human recombinant CYP enzymes, CYP3A4, 1A1 and 1B1, which are expressed at higher levels in tumors sensitive to ellipticine (i.e. breast and kidney cancer) than in peritumoral tissues ${ }^{34-37}$, were found to most efficiently activate ellipticine to form covalent DNA adducts in vitro ${ }^{22}$ (Fig. 5). Deoxyguanosine was identified as the target base to which ellipticine metabolites generated by CYPs are bound ${ }^{27}$, forming the two major ellipticine-derived DNA adducts (adduct spots 1 and 2 in Fig. 1) in vitro ${ }^{22,24,27}$. These deoxyguanosine adducts with ellipticine were detected in human hepatic ${ }^{27}$ and renal microsomes ${ }^{30}$, in V79 Chinese hamster lung fibroblasts transfected with human CYP3A4, 1A1 and $1 \mathrm{~A} 2^{23}$, in human breast adenocarcinoma MCF-7 cells ${ }^{26}$, in human HL60 leukemia cells ${ }^{28}$ and in several organs such as liver, kidney, lung, spleen, heart and brain of rats exposed to this anticancer drug ${ }^{25}$. Since CYP3A4 enzymatic activity

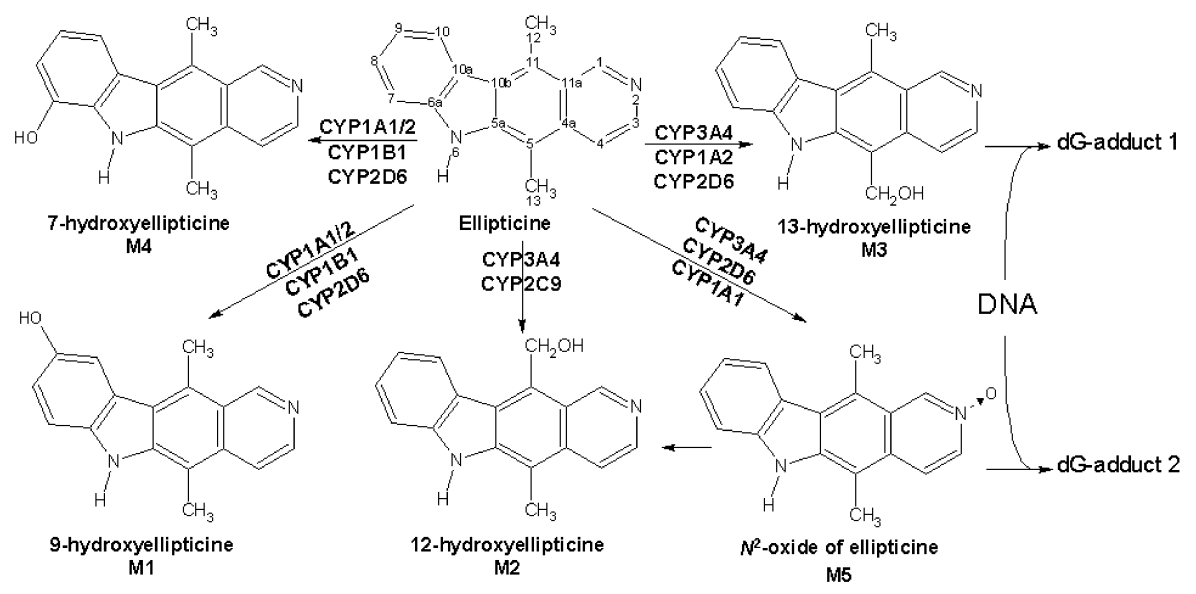

Fig. 3. Metabolism of ellipticine by human CYPs showing the metabolites and CYPs responsible for their formation. 

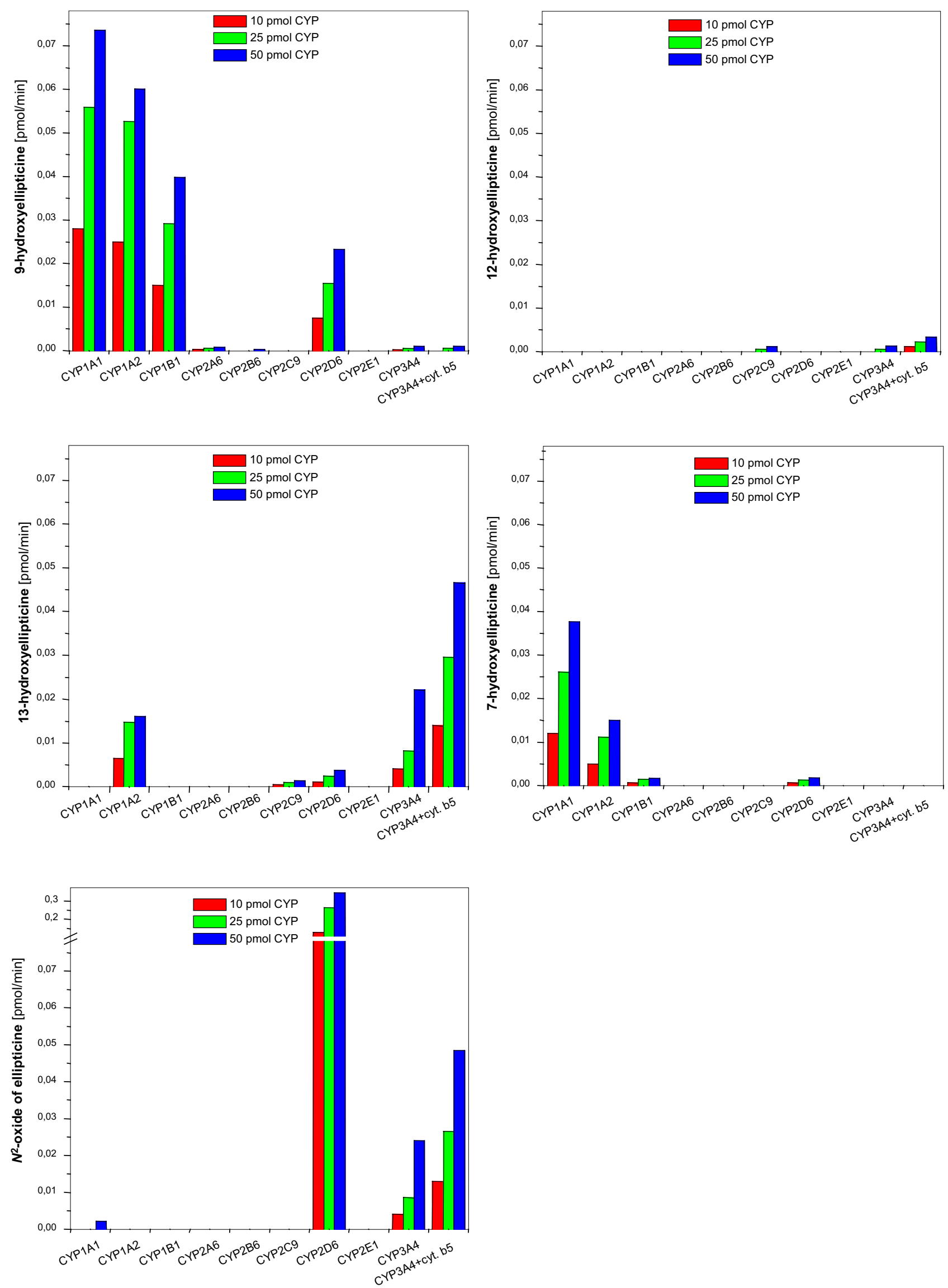

Fig. 4. Oxidation of ellipticine by human recombinant CYPs. 10-50 pmol human recombinant CYP/incubation and $10 \mu \mathrm{M}$ ellipticine were used in all experiments. Values of ellipticine metabolites are averages of triplicate incubations. Standard deviations were $\leq 10 \%$, [adapted from reference ${ }^{27}$ ]. 
correlated with levels of these DNA adducts formed in human hepatic microsomes, CYP3A4 seems to be the major enzyme generating these DNA adducts in human livers (Table 1). The orthologous rat enzymes, CYP3A1 and, furthermore, CYP1A1/2 are the enzymes responsible for DNA adducts formation in rats treated with ellipticine ${ }^{25}$. Besides these two major adducts, up to five minor adduct spots were detectable in DNA reacted with ellipticine activated with CYPs (ref. ${ }^{22,27}$ ) or in V79 (ref. ${ }^{23}$ ), MCF-7 (ref. ${ }^{26}$ ) and HL-60 cells ${ }^{28}$ exposed to ellipticine or in vivo ${ }^{25}$ (Fig. 6A $\mathrm{A}_{\mathrm{f}}$.

At the present time, it is not possible to demonstrate if the antitumor, cytostatic and/or genotoxic activities of ellipticine are related to only one or several of the DNA damage effects. Recently, we demonstrated that the cytotoxicity elicited by ellipticine towards Chinese hamster fibroblast V79 cells does not seem to be dependent on CYP expression ${ }^{23}$. Acute toxicity to these cells could be caused by the parent compound or by CYP independent metabolites. For ellipticine antitumour activity to cancer cells, however, other properties such as mutagenicity caused by DNA adducts, might be relevant. Indeed, Rekha and Sladek ${ }^{38}$ demonstrated that antineoplastic activity of ellipticine to MCF-7 cells depends on the levels of CYP enzymes activating ellipticine to DNA-binding species. These authors showed that MCF-7 cells treated with 3methylcholanthrene transiently expressed elevated levels of CYP1A and cells were transiently much more sensitive to ellipticine. CYP1A also activate ellipticine to species binding to $\mathrm{DNA}^{22-24}$ and in an earlier study we found the typical ellipticine-DNA adducts in these cells ${ }^{26}$. The CYPdependent higher sensitivity of MCF-7 cells to ellipticine observed by these authors might, therefore, be explained by ellipticine-DNA adduct formation.

Another important feature relating the expression of CYP and the antineoplastic activity of ellipticine was detected in MCF-7 cells selected for resistance to adriamycin (Adr $\left.{ }^{\mathrm{R}} \mathrm{MCF}-7\right)$ and exhibiting the phenotype of multidrug resistance (MDR) (ref. ${ }^{39}$ ). Ivy et al. ${ }^{39}$ postulated that the MDR property of $\mathrm{Adr}^{\mathrm{R}} \mathrm{MCF}-7$ cells involves several biochemical and genetic changes. One of them is a regulatory defect at the level of CYP1A1 mRNA resulting in lower CYP1A1-mediated metabolism of xenobiotics in these cells. $\mathrm{Adr}^{\mathrm{R}} \mathrm{MCF}-7$ cells are cross-resistant to ellipticine ${ }^{39}$, which we would explain by a decrease in the CYP1A1dependent activation of ellipticine. Taken together, the activities and expression levels of CYP enzymes, which effectively activate ellipticine to metabolites forming DNA adducts, may be important factors in the specificity of ellipticine for breast cancer. Nevertheless, to confirm this suggestion, formation of ellipticine-DNA adducts in breast cancer tissues in vivo remains to be evaluated. Preliminary results indicate that ellipticine-derived DNA adducts are detectable not only in healthy organs of rats exposed to ellipticine ${ }^{25}$, but also in the target tissue for the treatment, mammary tumors (Stiborová et al., unpublished results). Furthermore, to better understand the role of ellipticineDNA adducts in the pharmacological efficacy in the cancer treatment or in the genotoxic side effects of the drug, we are analyzing the dose dependence and the persistence

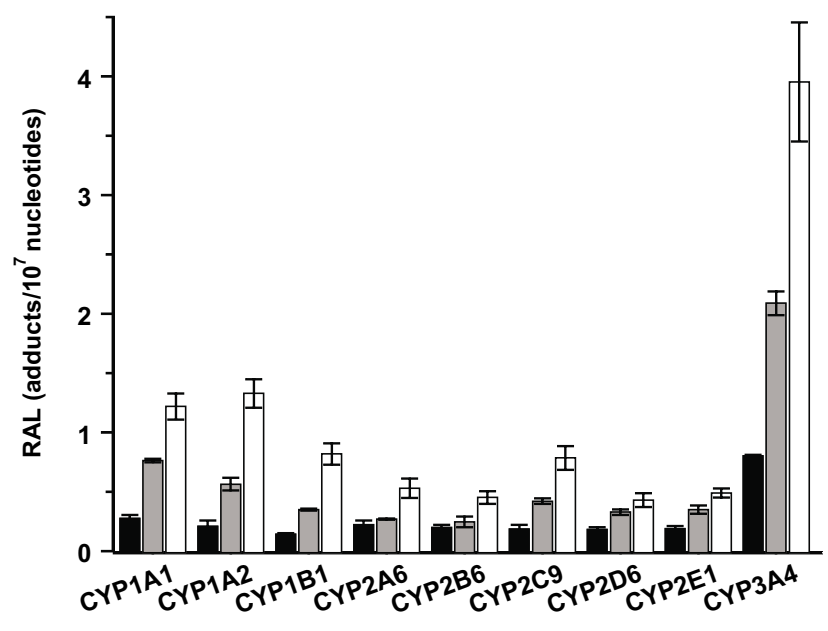

Fig. 5. Ellipticine-DNA adducts generated by human recombinant CYPs. [adapted from reference ${ }^{22}$ ]. All results are presented as the mean \pm SD from three incubations; each DNA sample was determined by two postlabeled analyses. RAL, relative adduct labeling. Levels of DNA adducts formed by 10 (black bars), 25 (grey bars) and $50 \mathrm{pmol}$ CYP (white bars) in incubations are shown [see reference ${ }^{22}$.

of ellipticine-DNA adducts in target and non-target tissues of rats treated with ellipticine. Because ellipticine is used in the treatment of breast cancer, differences in adduct patterns in the two sexes are also under investigation.

9-Hydroxyellipticine, the metabolite excreted in urine by humans (mainly in the form of conjugates), and 7hydroxyellipticine, were supposed to be the ellipticine detoxication products ${ }^{5}$. Indeed, their formation does not lead to generation of DNA adducts found in vivo, in rats treated with ellipticine ${ }^{25-27}$. On the contrary, we demonstrated that 13-hydroxy-, 12-hydroxyellipticine and the $N^{2}$-oxide of ellipticine, are the metabolites generating the two major deoxyguanosine adducts in DNA in vitro and in vivo of several organs of rats treated with ellipticine. The identities of these deoxyguanosine adducts formed from 13-hydroxy- and 12-hydroxyellipticine with those formed in vitro using CYP-dependent activation systems and in rats in vivo was proved by co-chromatography on TLC and HPLC $^{23-27,30}$ (see also Fig. 6 showing the TLC and HPLC profiles of these two adducts). Therefore, 13-hydroxy- and 12-hydroxyellipticine are the products of the activation pathway of ellipticine metabolism. 12-Hydroxyellipticine is formed in two ways, one by direct oxidation, and one by Polonowski rearrangement ${ }^{40,41}$ of ellipticine $N^{2}$-oxide ${ }^{27}$. Therefore, the formation of 12-hydroxyellipticine or ellipticine $N^{2}$-oxide, followed by its spontaneous rearrangement to 12-hydroxyellipticine, are two pathways leading to the formation of the same reactive species binding to DNA. Indeed, the production of ellipticine $N^{2}$-oxide in human hepatic microsomes correlated with levels of DNA adduct 2 formation (Table 1). 


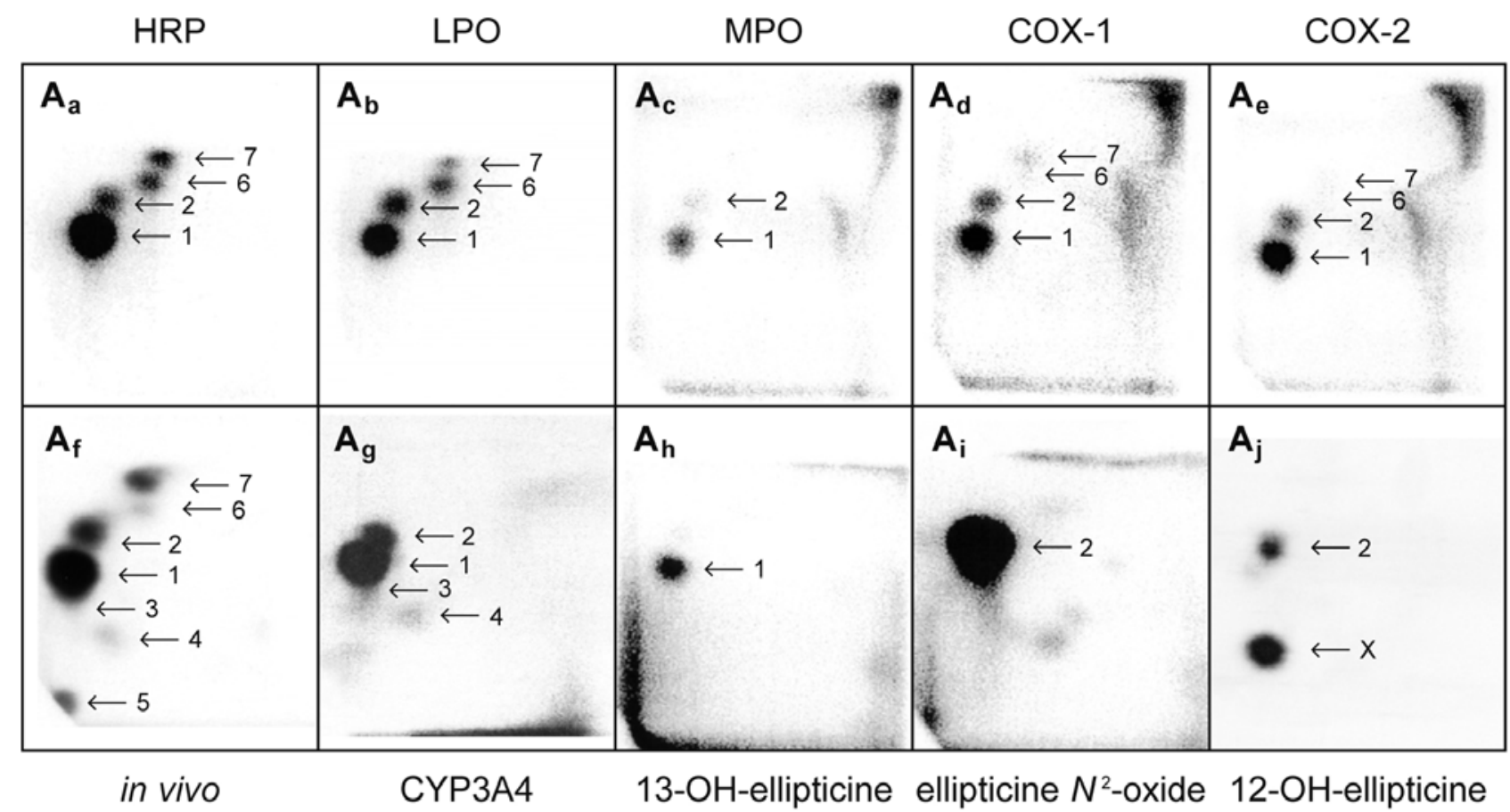

Adduct 1 from 13-OH-ellipticine

Adduct 2 from 12-OH-ellipticine

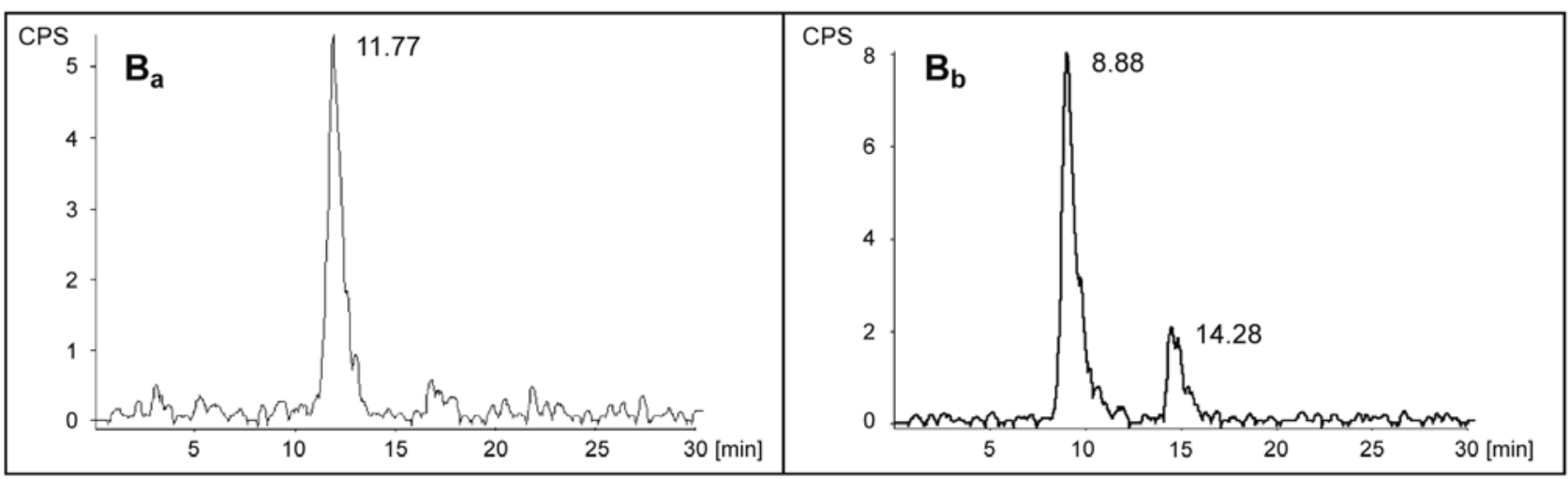

Fig. 6. Autoradiographic profiles of ellipticine-derived DNA adducts analyzed with the ${ }^{32} \mathrm{P}$-postlabeling assay (panels $A$ ) and HPLC profiles of adduct spots 1 and 2 generated in DNA by 13-hydroxyellipticine and 12-hydroxyellipticine, respectively (panels $B$ ). Adduct profiles obtained from calf thymus DNA reacted with ellipticine $(100 \mu \mathrm{M})$ and plant HRP $\left(\mathrm{A}_{\mathrm{a}}\right)$, bovine LPO $\left(\mathrm{A}_{\mathrm{b}}\right)$, human MPO $\left(\mathrm{A}_{\mathrm{c}}\right)$, ovine COX-1 $\left(\mathrm{A}_{\mathrm{d}}\right)$, human COX-2 $\left(\mathrm{A}_{\mathrm{e}}\right)$ ( $5 \mu \mathrm{g}$ peroxidases were present in the incubations), from liver DNA of rats treated with $40 \mathrm{mg}$ ellipticine per kilogram body weight $\left(\mathrm{A}_{\mathrm{f}}\right)$, from calf thymus DNA reacted with ellipticine and human CYP3A4 ( $\mathrm{A}_{\mathrm{g}}$ ), with 13hydroxyellipticine $\left(\mathrm{A}_{\mathrm{h}}\right)$, ellipticine $N^{2}$-oxide $\left(\mathrm{A}_{\mathrm{i}}\right)$ and 12-hydroxyelipticine $\left(\mathrm{A}_{\mathrm{j}}\right)$, [adapted from reference ${ }^{27}$ ].

2.1.2. Oxidation of ellipticine by peroxidases: another way to metabolic activation of ellipticine leading to DNA adduct formation

While CYP enzymes are abundantly expressed in several tissues, in which the DNA adducts were detected in vivo (i.e livers) (ref. ${ }^{25}$ ), and in some target cancers like breast and kidney cancer ${ }^{34-37}$, their levels are much lower in some other tissues or tumor cells (i.e. leukemia cells) that are sensitive to ellipticine. Indeed, ellipticine is cytotoxic to HL-60 promyelocytic leukemia cells and generates the DNA adducts in these cells ${ }^{28}$ even though they express low levels of CYP ${ }^{42}$. The question thus arises, which other enzymes are involved in ellipticine activation in these malignant tissues. Peroxidases expressed in some cancer cells might be good candidates for such ellipticine activation $^{42-53}$.

In the mid 1980s the group of B. Meunier studied binding of one radioactively labeled ellipticine derivative, the antitumour drug 9-hydroxy- $N^{2}$-methylellipticinium to DNA or RNA upon oxidation by horseradish peroxidase (HRP) $)^{5,54-56}$. They and others proposed a mechanism by which this and other 9-hydroxylated ellipticine derivatives ${ }^{5,54-60}$ can act as bioalkylating agents ${ }^{60-63}$. These compounds are oxidized to the quinone-imine which then undergoes regiospecific Michael-type addition of bionucleophiles at the 10-position of quinone-imine yielding 


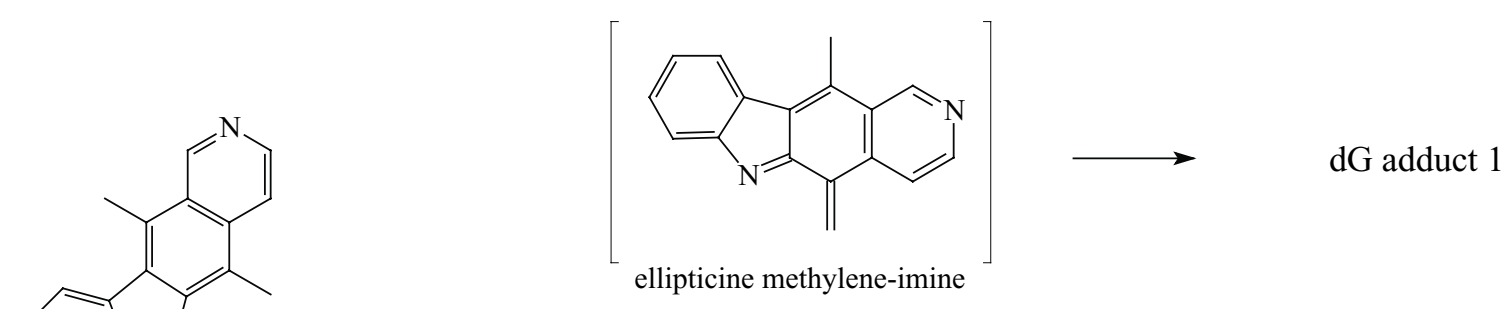<smiles></smiles>

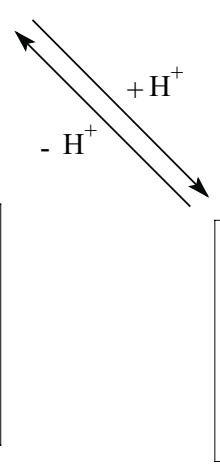<smiles>Cc1c2cnccc2c(C)c2c1[nH]c1ccccc12</smiles>

ellipticine-13-ylium<smiles>OCc1c2ccncc2c(I)c2[nH]c3ccccc3c12</smiles>

13-hydroxyellipticine

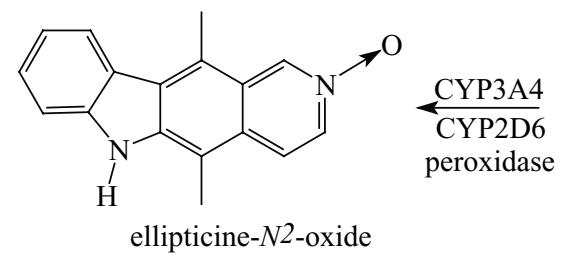<smiles>Cc1c2ccncc2c(C)c2c1[nH]c1ccccc12</smiles>

Polonowski rearrangement

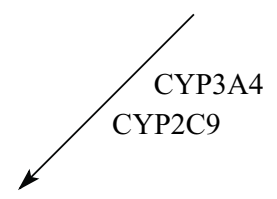<smiles>Cc1c2ccncc2c(CO)c2c1[nH]c1ccccc12</smiles>

12-hydroxyellipticine

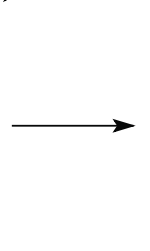

$$
[
$$

$\longrightarrow \quad$ dG adduct 2

Fig. 7. Metabolism of ellipticine by peroxidases and human CYPs showing the characterized metabolites and those proposed to form DNA adducts. The compounds shown in brackets were not detected under the experimental conditions used in the experiments and are the electrophilic metabolites postulated as ultimate arylating species, [adapted from reference ${ }^{30}$ ].

the adduct product with nucleophiles. Such adducts have been chemically prepared by oxidation of 9-hydroxyellipticine in the presence of nucleophiles by Meunier's ${ }^{59,61}$ and Potier's ${ }^{62,63}$ research groups. The non-hydroxylated ellipticine derivatives were found by these authors not to be oxidized and to bind only very weakly to DNA ${ }^{54}$. In contrast to these results, our studies indicate that ellipticine is easily and effectively oxidized by peroxidases to species that bind to $\mathrm{DNA}^{28-30}$.

Peroxidases such as bovine lactoperoxidase (LPO), human myeloperoxidase (MPO), ovine cyclooxygenase
(COX)-1, human COX-2 and plant HRP oxidize ellipticine to species binding to DNA. Such activation was also found in incubations with one human renal microsomal sample in the presence of arachidonic acid, a cofactor of $\mathrm{COX}^{30}$. Using two independent methods, ${ }^{32} \mathrm{P}$-postlabeling and ${ }^{3} \mathrm{H}$-labeled ellipticine, we showed that ellipticine binds covalently to DNA in vitro after its oxidation by the peroxidases. During the elllipticine oxidation by peroxidases in vitro, two ellipticine metabolites were detectable under the conditions used in our experiments (Fig. 6). The major one was characterized by NMR spectroscopy as 
the ellipticine dimer, where two ellipticine residues are connected via the nitrogen atom $N^{6}$ in the pyrrole ring of one of the ellipticine molecules and the carbon atom $\mathrm{C} 9$ of the second ellipticine ${ }^{30}$ (Fig. 7). The mechanism by which the ellipticine dimer is generated was resolved ${ }^{29,30}$. We showed that peroxidases metabolize ellipticine in a one-electron oxidation to free radicals, which, depending on the environment, generate either the additional metabolites such as ellipticine dimer or DNA adducts. Taking the structure of the dimer into account (Fig. 7), the first radical would be on the secondary nitrogen atom of the pyrrole ring $\left(N^{6}\right)$. It should be noted that the dimer product is much less likely to be formed physiologically than in this experimental system, because no other molecules (bionucleophiles) are present there to intercept ellipticine reactive intermediates. Indeed, during the ellipticine oxidation by peroxidases in the presence of DNA up to four DNA adducts are formed, and an increase in the formation of the major DNA adduct 1 correlates with a decrease in generation of the ellipticine dimer ${ }^{30}$. Hence, ellipticine-DNA adduct formation seems to be the preferential reaction under the physiological conditions.

Even though a two-electron-oxidation metabolite such as methylene-imine (Fig. 7) was not found to be formed from ellipticine under the conditions used in our experiments $^{29,30}$, we still suggest that such an ellipticine metabolite is responsible for the formation of the major ellipticine-DNA adduct (spot 1 in Figs. 1 and 6). This suggestion is strongly supported by our finding that the optimal adduct 1 formation required stoichiometric equivalents of ellipticine and oxidizing co-substrate, hydrogen peroxidase, during the peroxidase-mediated oxidation of ellipticine ${ }^{30}$.

As shown in Fig. 6, this adduct is generated from 13hydroxyellipticine ${ }^{27}$ The exact reactive species as well as the positions in guanine where the reactive species generated from 13-hydroxyellipticine are bound remain to be elucidated. Nevertheless, we have suggested ${ }^{27}$ that $13-$ hydroxyellipticine might, depending on the environment, decompose spontaneously to the reactive carbenium ion (Fig. 7), which reacts with one of the nucleophilic centers in the deoxyguanosine residue in DNA (i.e. the exocyclic $-\mathrm{NH}_{2}$ group of guanine). The identity of the adduct 1 generated from 13-hydroxyellipticine with that formed by peroxidases allow us to estimate the structure of a two-electron oxidation metabolite of ellipticine responsible to its formation as the methylene-imine derivative of ellipticine (Fig. 7). Such a reactive compound would generate an identical carbenium ion as 13-hydroxyellipticine (ellipticine-13-ylium, Fig. 7). In other words, 13-hydroxyellipticine acts as precursor of the vinylogous imine intermediate (methylene-imine) (Fig. 7), Michael-type addition of nucleophiles to this vinylogous imine then yields an adduct identical to that formed by the carbenium ion ${ }^{64}$.

The minor ellipticine oxidation product formed by peroxidases is the ellipticine $N^{2}$-oxide, thus, the same metabolite that is also generated by human CYP enzymes ${ }^{27}$. As mentioned above, an $N^{2}$-oxidation of ellipticine was found to be the prerequisite for the formation of 12-hydroxyellipticine metabolite (by the Polonowski rearrangement ${ }^{27,43,44}$ ), which is responsible for generation of the second deoxyguanosine adduct in DNA (spot 2 in Figs. 1 and 6$)^{27}$. Indeed, the identical DNA adduct was generated from ellipticine after its activation by peroxidases. As in the case of 13-hydroxyellipticine, we postulate another carbenium ion reacting with the nucleophillic centers of deoxyguanosine in DNA, generating the DNA adduct 2 (Fig. 7).

Two additional adducts (spots 6 and 7 in Fig. 6) formed in DNA by ellipticine activated with peroxidases were also observed in incubations with human hepatic ${ }^{27}$ and renal microsomes ${ }^{30}$ and in DNA of several tissues of rats treated with ellipticine ${ }^{25}$ Peroxidase oxidation of ellipticine leads to much higher levels of these adducts than are formed in vivo ${ }^{25}$ or in incubations with hepatic microsomes ${ }^{27}$ Other minor ellipticine-DNA adducts found in vivo (spots 3-5 in Fig. 6), however, were not detectable in the peroxidase activation system. The mechanism of formation of these minor adducts and their structural characterization remains to be investigated.

Although HRP might only serve as a model peroxidase, the findings that MPO, LPO, COX-1 and COX-2 are effective in ellipticine oxidation may be of greater significance. Human MPO is expressed in acute myeloblastic leukemia ${ }^{43,53}$, and might be involved in metabolic activation of drugs including ellipticine in leukemic myeloblasts ${ }^{42,52}$. Because of the high expression of this enzyme in acute myeloblastic leukemia, it is also used as a diagnostic marker in this leukemia. In addition, human MPO expressed in neutrophils and present in milk and blood ${ }^{46,56}$ might, besides CYPs, participate in metabolism of ellipticine in other cancers ${ }^{42,52}$. Likewise, LPO is secreted by human mammary ductal epithelial cells into the breast duct ${ }^{46}$ and might metabolize anticancer drugs including ellipticine in other cancers ${ }^{65}$. Namely, like other lipophilic compounds ellipticine may accumulate in fatty tissues, such as the breast, and depending on the levels of activating enzymes present (e.g. LPO and MPO) ellipticine can be oxidized to intermediates modifying key molecules such as DNA in this tissue. Hydrogen peroxide, required for peroxidase-mediated oxidations, comes from respiratory burst of neutrophils and is also supplied by xanthine oxidase ${ }^{65,66}$.

The finding that ovine COX-1 and human COX-2 are capable of oxidative activation of ellipticine seems to have even greater significance. COX-1 is constitutively expressed with near constant levels and activity in many tissues and in several tumors (i.e. in brain tumors) ${ }^{67}$. Moreover, overexpression of COX-2 was demonstrated in multiple cancer types (i.e. carcinomas and brain tumors) and some pre-neoplastic lesions and is even inducible by carcinogenic processes and/or by several compounds, including anticancer drugs ${ }^{44,46-50}$. Even though the effect of ellipticine on COX-2 expression has not yet been investigated, this peroxidase may play an important role in ellipticine metabolic activation in cancer cells, in which low levels of CYP enzymes are expressed. Therefore, a detailed study analyzing the relationships between lev- 
els of DNA-adducts formed from ellipticine activated by peroxidases, and expression levels of these enzymes and ellipticine cytotoxicity in human leukemia cells is under way in our laboratory. The objective to investigate the participation of peroxidases in the metabolic activation of ellipticine in vivo is our next goal. For instance, MPOknockout mice may help to evaluate the involvement of this enzyme in the bioactivation of ellipticine in vivo ${ }^{68}$.

\section{ACKNOWLEDGEMENT}

This work was supported by Grant Agency of the Czech Republic (grant 203/06/0329) and Ministry of Education of the Czech Republic (grant MSM0021620808).

\section{REFERENCES}

1. Dalton LK, Demerac S, Elmes BC, Loder JW, Swan JM, Teitei T. (1967) Synthesis of the tumor-inhibitory alkaloids, ellipticine, 9-methoxyellipticine, and related pyrido-[4,3-b]carbazoles. Aust J Chem 20, 2715-2727.

2. .Rouesse JG, Le Chevalier T, Caille F, Mondesir JM., SanchoGamier H., May-Levin F Spielman M, DeJager R, Amiel JL.(1985) Phase II study of ellipticinium in advanced breast cancer. Cancer Treat Rep 69, 707-708.

3. Mathe G, Triana K, Pontiggia P, Blanquet D, Hallard M, Morette C. (1998) Data of pre-clinical and early clinical trials of acriflavine and hydroxy-methyl-ellipticine reviewed, enriched by the experience of their use for 18 months to 6 years in combination with other HIV1 virostatic. Biomed Pharmacother 52, 391-396.

4. Goodwin S, Smith AF, Horning EC. (1959) Alkaloids of Ochrosia elliptica Labill. J Am Chem Soc 81, 1903-1908.

5. Auclair C. (1987) Multimodal action of antitumor agents on DNA: The ellipticine series. Arch Biochem Biophys 259, 1-14.

6. Boyd MR.(1989) Status of the NCI preclinical antitumor drug discovery screen: Implications for selection of new agents for clinical trials. In: DeVita VT Jr, Hellman S and Rosenburg S, Editors. Cancer: Principles and Practice of Oncology Updates. vol. 3, Philadelphia: Lippincott, p. 1-12.

7. Boyd MR. (1993) The future of drug development. In: Niederhuber JE, Editor. Current Therapy in Oncology. Philadephia: B.C. Decker, p. 11-22.

8. Acton EM, Narayanan VL, Risbood PA, Shoemaker PH, Vistica DT, Boyd MR. (1994) Anticancer specificity of some ellipticinium salts against human brain tumors in vitro. J Med Chem 37, 2185-2189.

9. Arguello F, Alexander MA, Greene JF Jr, Stinson SF, Jorden JL, Smith EM, Kalavar NT, Alvord WG, Klabansky RL, Sausville EA. (1998) Preclinical evaluation of 9-chloro-2-methylellipticinium acetate alone and in combination with conventional anticancer drugs to treatment of human brain tumor xenografts. J Cancer Res Clin Oncol 124, 19-26.

10. DeMarini DM, Abu-Shakra A, Gupta R, Hendee LJ, Levine JG. (1992) Molecular analysis of mutations induced by the intercalating agent ellipticine at the hisD3052 allele of Salmonella typhimurium TA98. Environ Mol Mutagenesis 20, 12-18.

11. Singh MP, Hill GC, Peoc'h D, Rayner B, Inabach JL, Lown JW. (1994) High-field NMR and restrained molecular modeling studies on a DNA heteroduplex containing a modified apurinic abasic site in the form of covalently linked 9-aminoellipticine. Biochemistry 33, 10271-10285.

12. Chu Y, Hsu MT. (1992) Ellipticine increases the superhelical density of intracellular SV40 DNA by intercalation. Nucleic Acids Res 20, 4033-4038.
13. Monnot M, Mauffret O, Simon V, Lescot E, Psaume B, Saucier JM, Charra M, Belehradek JJr, Fermandjian S. (1991) DNA-drug recognition and effects on topoisomerase II-mediated cytotoxicity. A three-mode binding model for ellipticine derivatives. J Biol Chem $25,1820-1829$.

14. Fossé P, René B, Charra M, Paoletti C, Saucier JM. (1992) Stimulation of topoisomerase II-mediated DNA cleavage by ellipticine derivatives: structure-activity relationships. Mol Pharmacol 42, 590-595.

15. Froelich-Ammon SJ, Patchan MW, Osheroff N, Thompson RB. (1995) Topoisomerase II binds to ellipticine in the absence or presence of DNA. Characterization of enzyme-drug interactions by fluorescence spectroscopy. J Biol Chem 270, 14998-1504.

16. Peng Y, Li C, Chen L, Sebti S, Chen J. (2003) Rescue of mutant p53 transcription function of ellipticine. Oncogene 22, 44784487.

17. Sugikawa E, Hosoi T, Yazaki N, Gamanuma N, Nakanishi N, Ohashi M. (1999) Mutant p53 mediated induction of cell cycle arrest and apoptosis at G1 phase by 9-hydroxyellipticine. Anticancer Res 19, 3099-3108.

18. Ohashi M, Sugikawa E, Nakanishi N. (1995) Inhibition of p53 protein phosphorylation by 9-hydroxyellipticine: A possible anticancer mechanism. Jpn J Cancer Res 86, 819-829.

19. Kuo PL, Hsu Y, Chang C, Lin C. (2005) The mechanism of ellipticine-induced apoptosis and cell cycle arrest in human breast MCF-7 cancer cells. Cancer Lett 223, 293-301.

20. Schwaller MA, Allard B, Lescot E and Moreau F. (1995) Protonophoric activity of ellipticine and isomers across the energy-transducing membrane of mitochondria. J Biol Chem 270, 22709-22713.

21. Hagg M, Berndtsson M, Mandic A, Zhou R, Shoshan MC, Linder S. (2004) Induction of endoplasmic reticulum stress by ellipticine plant alkaloids. Mol Cancer Ther 3, 489-497.

22. Stiborová M, Bieler CA, Wiessler M, Frei E. (2001) The anticancer agent ellipticine on activation by cytochrome $\mathrm{P} 450$ forms covalent DNA adducts. Biochem Pharmacol 62, 675-684.

23. Frei E, Bieler CA, Arlt VM, Wiessler M, Stiborová M. (2002) Covalent binding of the anticancer drug ellipticine to DNA in V79 cells transfected with human cytochrome P450 enzymes. Biochem Pharmacol 64, 289-295.

24. Stiborová M, Stiborová-Rupertová M, Bořek-Dohalská L, Wiessler M, Frei E. (2003) Rat microsomes activating the anticancer drug ellipticine to species covalently binding to deoxyguanosine in DNA are a suitable model mimicking ellipticine bioactivation in humans. Chem Res Toxicol 16, 38-47.

25. Stiborová M, Breuer A, Aimová D, Stiborová-Rupertová M, Wiessler M, Frei E. (2003) DNA adduct formation by the anticancer drug ellipticine in rats determined by ${ }^{32} \mathrm{P}$-postlabeling. Int J Cancer 107, 885-890.

26. Bořek-Dohalská L, Frei E, Stiborová M. (2004) DNA adduct formation by the anticancer drug ellipticine and its hydroxy derivatives in human breast adenocarcinoma MCF-7 cells. Collect Czech Chem Commun 69, 603-615.

27. Stiborová M, Sejbal J, Bořek-Dohalská L, Aimová D, Poljaková J, Forsterová K, Rupertová M, Wiesner J, Hudeček J, Wiessler M, Frei E. (2004) The anticancer drug ellipticine forms covalent DNA adducts, mediated by human cytochromes $\mathrm{P} 450$, through metabolism to 13-hydroxyellipticine and ellipticine $N^{2}$-oxide. Cancer Res 64, 8374-8380.

28. Poljaková J, Stiborová M. (2004) Peroxidase-mediated ellipticineDNA adduct formation explains the selective efficiency of this anticancer drug against breast cancer and leukemia. Chem Listy 98 , 298.

29. Poljaková J, Forsterová K, Šulc M, Frei E, Stiborová M. (2005) Oxidation of ellipticine by peroxidases. Biomed Papers 149, 449453.

30. Stiborová M, Poljaková J, Ryšlavá H, Dračínský M, Eckschlager T, Frei E. (2006) Mammalian peroxidases activate anticancer drug ellipticine to intermediates forming deoxyguanosine adducts in DNA identical to those found in vivo and generated from 12-hydroxyellipticine and 13-hydroxyellipticine. Int J Cancer, submitted. 
31. Stiborová M, Bořek-Dohalská 1, Aimová D, Kotrbová V, Kukačková K, Janouchová K, Rupertová M, Ryšlavá H, Hudeček J, Frei E. (2006) Oxidation pattern of the anticancer drug ellipticine by hepatic microsomes - similarity between human and rat systems. Gen Physiol Biophys, in press.

32. Rendic S, DiCarlo FJ. Human cytochrome P450 enzymes: A status report summarizing their reactions, substrates, inducers, and inhibitors. Drug Metab Rev 1997; 29: 413-80.

33. Stiborová M, Rupertová M, Hodek P, Frei E, Schmeiser HH. (2004) Monitoring of DNA adducts in humans and ${ }^{32} \mathrm{P}$-postlabelling methods. A review. Collect Czech Chem Commun 69, 477-498.

34. Murray GI., Weaver RJ, Paterson PJ, Ewen SW, Melvin WT, Burke MD. (1993) Expression of xenobiotic metabolizing enzymes in breast cancer. J Pathol 169, 347-353.

35. Murray GI, Melvin WT, Burke M. Cytochrome P450 expression in tumors. (1995) J Pathol 176, 323-324.

36. Patterson LH, McKeown SR, Robson T, Gallagher R, Raleigh SM, Orr S. Antitumor prodrug development using cytochrome P450 (CYP) mediated activation. Anti-Cancer Drug Design 1999; 14:473-86.

37. El-Rayes BF, Ali S, Heilbrun LK, Lababidi S, Bouwman S, Vischer D, Philip PA. (2003) Cytochrome P450 and glutathione transferase expression in human breast cancer. Clin Cancer Res 9, 1705-1709.

38. Rekha GK, Sladek NE. (1997) Multienzyme-mediated stable and transient multidrug resistance and collateral sensitivity induced by xenobiotics. Cancer Chemother Pharmacol 40, 215-224.

39. Ivy SP, Tulpule A, Fairchild CR, Averbuch SD, Myers CE, Nebert DW, Baird WM, Cowan KH. (1988) Altered regulation of P-450IA1 expression in a multidrug-resistant MCF-7 human breast cancer cell line. J Biol Chem 263, 19119-19125.

40. Hofle G, Glase N, Leibold T, Sefkow M. Epothilone A-D and their thiazole-modified analogs as novel anticancer agents. Pure Appl Chem 1999; 71: 2019-24.

41. Nicolaou KC, Ritzén A, Namoto K. (2001) Recent developments in the chemistry, biology and medicine of the epothilones. Chem Commun 1523-1535.

42. Schlaifer D, Meyer K, Muller C, Attal M, Smith MT, Tamaki S, Weimels J, Pris J, Jaffrezou JP, Laurent G, Myers CE. (1994) Antisense inhibition of myeloperoxidase increases the sensitivity of the HL-60 cell line to vincristine. Leukemia 8, 289-291.

43. Lübbert M, Miller CW, Koeffler HP. (1991) Changes of DNA methylation and chromatin structure in the human myeloperoxidase gene during myeloid differentiation. Blood 78, 345-356.

44. Hoy A, Leininger-Muller B, Jolivalt C, Siest G. (2000) Effect of apolipoprotein $\mathrm{E}$ on cell viability in a human neuroblastoma cell line: influence of oxidation and lipid-association. Neurosci Lett 285, $173-176$

45. Kirschenbaum A, Klausner AP, Lee R, Unger P., Yao S., Kiu X.H.,.Levine A.C. (2000) Expression of cyclooxygenase-1 and cyclooxygenase-2 in the human prostate. Urology 56, 671-676.

46. Williams JA, Phillips DH. (2000) Mammary expression of xenobiotic metabolizing enzymes and their potential role in breast cancer. Cancer Res 60, 4667-4677.

47. Soslow RA, Dannenberg AJ, Rush D, Woemer B.M., Khan KM, Masferrerer J., Koki AT. (2000) COX-2 is expressed in human pulmonary, colonic, and mammary tumors. Cancer 89, 2637-2645.

48. Matsuo M, Yonemitsu N, Zaitsu M, Ishii K, Hamasaki Y, Fukuyama K, Tabuchi K, Miyazaki S. (2001) Expression of prostaglandin H synthase-2 in human brain tumors. Acta Neuropathol 102, 181187.

49. Shono T, Tofilon PJ, Bruner JM, Owolabi O, Lang FF. (2001) Cyclooxygenase-2 expression in human gliomas: Prognostic significance and molecular correlations. Cancer Res 61, 4375-4381.

50. Peng JP, Su CY, Chang HC, Chai CY, Hung WC. (2002) Overexpression of cyclo-oxygenase 2 in squamous cell carcinoma of the hypopharynx. Human Pathol 33, 100-104.
51. Castilla EA, Prayson RA, Kanner AA, Rybicky LA., Tubbs R.R., Vogelbaum M.A., Barnett G.H. (2003) Cyclooxygenase-2 in oligodendroglial neoplasms. Cancer 8, 1465-1472.

52. Ludwig-Muller J, Tokalov SV, Franz A, Gutzeit HO. (2005) Quercetin metabolism in vital and apoptotic human leukaemia cells. Biol Chem 386, 279-283.

53. Schmelz K, Sattler N, Wagner M, Lübbert M, Dorken B, Tamm I. (2005) Induction of gene expression by 5-aza-2'-deoxycytidine in acute myeloid leukemia (AML) and myelodysplastic syndrome (MDS) but not epithelial cells by DANN-methylation-dependent and -independent mechanisms. Leukemia 19, 103-111.

54. Auclair C, Dugué B, Meunier B, Paoletti C. (1986) Peroxidasecatalyzed covalent binding of the antitumor drug $N^{2}$-methyl-9-hydroxyellipticinium to DNA in vitro. Biochemistry 25, 1240-1245.

55. Dugué B, Auclair C, Meunier B. (1986) Covalent binding of elliptinium acetate (NSC 264137) to nucleic acids of L1210 cells in culture. Cancer Res 46, 3828-3833.

56. Dugue B, Paoletti C, Meunier B. (1984) Covalent binding of antitumor agent $N^{2}$-methyl-9-hydroxy-ellipticinium acetate (NSC 264137) on RNA and poly A in vitro. Biochem Biophys Res Commun 124, 416-422.

57. Bernadou J, Meunier G, Paoletti C, Meunier B. (1983) Orthoquinone formation in the biochemical oxidation of the anti-tumor drug $N^{2}$-methyl-9-hydroxyellipticinium acetate. J Med Chem 26 , 574-579.

58. Meunier G, Meunier B. (1985) Peroxidase-catalyzed O-demethylation reactions - quinone-imine fromation from 9-methoxyellipticine derivatives. J Biol Chem 260, 10576-10582.

59. Meunier G, Demontauzon D, Bernandou J, Grassy G, Bonnafous M, Cros S, Meunier B. (1988) The biooxidation of cyto-toxic ellipticine derivatives - a key to structure-activity relationship studies. Mol Pharmacol 33, 93-102.

60. Bernadou J, Bonnafous M, Labat G, Loiseau P, Meunier B. (1991) Model systems for metabolism studies - biomimetic oxidation of acetaminophen and ellipticine derivatives with water-soluble metalloporphyrins associated to potassium monopersulfate. Drug Metab Dispos 19, 360-365.

61. Pratviel G, Bernadou J, Ha T, Meunier G, Cros S., Meunier B, Gillet B, Guitret E. (1986) Ribose as the preferential target for the oxidized form of elliptinium acetate in ribonucleos(t)ides - biological-activities of the resulting adducts. J Med Chem 20, 1350-1355.

62. Kansal VK, Funakoshi S, Mangeney P, Gillet B, Guittet E, Lallemand JY, Potier P. (1985) Interaction of nucleosides with antitumoral agents - 9-hydroxy- $N^{2}$-methylellipticinium acetate and 9-hydroxy- $N^{2}$-methylolivacinium acetate. Tetrahedron 41, 51075120 .

63. Kansal VK, Potier P, Gillet B, Guittet E, Lallemand J-Y, HuynhDinh T, Igolen J. (1985) Regioselective and stereoselective alkylation at the 3'-terminal end of ribonucleotides by $N^{2}$-methyl9-hydroxyellipticinium acetate - an antitumor agent. Tetrahedron Lett 26, 2891-2894.

64. Donaghy MJ, Stanforch SP. (1999) Nucleophilic addition of fused benzimidazole $N$-oxide. Tetrahedron $55,1441-1448$.

65. Josephy PD. (1996) The role of peroxidase-catalyzed activation of aromatic amines in breast cancer. Mutagenesis 11, 3-7.

66. Gorlewska-Roberts KM, Teitel CH, Lay JO, Roberts DW, Kadlubar FF. (2004) Lactoperoxidase-catalyzed activation of carcinogenic aromatic and heterocyclic amines. Chem Res Toxicol 17, 16591666.

67. Yha S, Yegnasubramanian V, Nelson WG, Isaacs WB, De Marzo AM. (2004) Cyclooxygenases in cancer: progress and perspective. Cancer Lett 215, 1-20.

68. Noguchi N, Nakano K, Aratani Y, Koyama H, Kodama T, Niki E. J. (2000) The role of myeloperoxidase in neutrophil-induced oxidation of low density lipoprotein as studied by myeloperoxidaseknockout mouse. Biochem. (Tokyo) 127, 971-977. 